Volume 8 Issue 32016

DOl: $10.5959 /$ eimj.v8i3.454

\section{ARTICLE INFO}

Submitted: 01-08-2016

Accepted: 09-08-2016

Online: 30-09-2016

\title{
Prevalence of Burnout among Universiti Sains Malaysia Medical Students
}

\author{
Ri Wei Andrew Chin, Yun Yuan Chua, Min Ning Chu, Nur Farhanie \\ Mahadi, Muhammad Saiful Bahri Yusoff, Mung Seong Wong, Yeong \\ Yeh Lee \\ School of Medical Sciences, Universiti Sains Malaysia, Kota Bharu, \\ Kelantan
}

To cite this article: Chin RWA, Chua YY, Chu MN, Mahadi NF, Yusoff MSB, Wong MS, et al. Prevalence of burnout among Universiti Sains Malaysia medical students. Education in Medicine Journal. 2016;8(3):61-74. http://dx.doi.org/10.5959/eimj.v8i3.454

To link to this article: http://dx.doi.org/10.5959/eimj.v8i3.454

\section{ABSTRACT}

Introduction: The academic life of medical students can be considered as psychological toxic. About half of United States medical students experience burnout and more than $25 \%$ experience depression. This study aimed to determine the prevalence of burnout among medical students in a Malaysian medical school and its associated factors. Methods: This is a cross sectional study of 452 medical students from Universiti Sains Malaysia (USM). Copenhagen Burnout Inventory was distributed via Google Forms through Facebook Messenger. Ethical approval was obtained from the Human Research Ethics Committee USM. Data were collected via Google Sheets. Each respondent only submitted one Google Form as no resubmission link was provided once completed Google Form was submitted. Result: The prevalence of burnout among USM medical students was 67.9\%. Personal burnout was the highest $(81.6 \%)$, followed by work-related burnout $(73.7 \%)$ and client-related burnout $(68.6 \%)$. The analysis showed that regardless of year of study, gender and ethnicity (all $P>$ 0.05), USM medical students were vulnerable to burnout. Conclusion: The prevalence of burnout among USM medical students was high and the most prevalent type of burnout was personal burnout. Therefore, burnout among medical students should be a concern and must be addressed to prevent subsequent unwanted consequences.

Keywords: Burnout, Malaysia, Medical students, Student wellbeing, Higher education

CORRESPONDING AUTHOR

Ri Wei Andrew Chin, School of Medical Sciences, Universiti Sains Malaysia, Kota Bharu, Kelantan | Email: andrew9329@gmail.com

\section{Introduction}

In the historical development of the burnout concept, and also with a recent definition by one of the leading researchers in the field, Schaufeli; in 2001, burnout was defined as "a state of physical, emotional and mental exhaustion that results from long-term involvement in work situations that are emotionally demanding" (1). Interestingly, this definition is almost identical to the definition by Pines and Aronson from 1988 which defined burnout as "a state of physical and emotional exhaustion caused by longterm involvement in situations that are emotionally demanding" (2). Also Shirom (3), another central figure in burnout research, emphasised that fatigue and exhaustion should be considered the central features of the concept, which stated that "Specifically, burnout refers to a combination of physical fatigue, emotional exhaustion, and cognitive weariness" (3-5).

Burnout is characterised by three features that include emotional exhaustion, 
depersonalisation and reduced professional efficacy (6). Emotional exhaustion is manifested by emotional depletion from being overworked, depersonalisation is a sense of being unfeeling towards patients or peers (often negative, callous and detached responses), and reduced professional efficacy, a domain specific to human services industry, is a reduced sense of competence or achievement in one's work.

The academic life of medical students can be considered as psychologically toxic and the major source of stress was related to the academic requirements $(7-10)$. This is evidenced by a recent meta-analysis which revealed a high prevalence of depression among medical students across the globe the estimated prevalence was $28.0 \%(24.2 \%-$ $32.1 \%$ ) (11). In contrast, prior to entry into medical school, the prevalence of depression among these prospective medical students was only between $1.4 \%$ and $1.8 \%(8,12)$. In addition, more than half of students in United States medical schools reported burnout (13, 14). In a recent review, $35 \%-45 \%$ of medical students had high emotional exhaustion, $26 \%-38 \%$ had high depersonalisation and $45 \%-56 \%$ had symptoms suggestive of burnout (10). Since burnout can be considered as the stage before depression, therefore we hypothesised that the prevalence of burnout amongst medical students would be high.

Copenhagen Burnout Inventory (CBI), is a new tool measuring burnout in term of fatigue and exhaustion (5). It comprises three sub-dimensions that are - personal burnout, work-related burnout, and client-related burnout.

Personal burnout refers to degree of physical and psychological fatigue and exhaustion experienced by the person. The personal burnout scale was intentionally created to be sensitive at the negative end, for example, among persons with a relatively high level of fatigue or exhaustion. The personal burnout scale was also created to compare individuals regardless of occupational status (e.g. young people, unemployed, early retired and pensioners). However, no attempt was made to distinguish between physical and psychological fatigue and exhaustion. Workrelated burnout refers to degree of physical and psychological fatigue and exhaustion that is perceived by the person as related to his or her work. Hence, the work-related burnout scale focus on burnout symptoms related to attributes of his or her work. However, no intention was made to assess the cause of work-related burnout because people may attribute their symptoms to their work without any valid scientific reasons. The work-related burnout scale enables one to identify persons who are tired but attributed his/her fatigue to non-work factors like health problems or family demands. Client-related burnout refers to degree of physical and psychological fatigue and exhaustion that is perceived by the person as related to his or her work with clients. The clients is a broad concept covering terms such as patients, inmates, children, students, residents, etc.; hence, when CBI is used in practice, the term appropriate to the specific group of respondents is used (5). This clientrelated burnout scale is intended to assess the degree to which people see a connection between their fatigue and their peoplecentred work.

Based on an analysis on the baseline and follow-up from an on-going prospective study of burnout in employees in the human service sector (Also known as the PUMA Study [Project on Burnout, Motivation and Job Satisfaction]), it shows that CBI scales have high internal reliability and high face validity; as the questions are easy to understand and answer (5). The CBI has also been translated into a number of languages (namely English, Mandarin, Cantonese, Japanese, Swedish, Finnish, French and Slovenian) and is currently being used in many countries (5). From a scientific point of view, the CBI is freely available in the public domain with its open access, unlike the Maslach Burnout Inventory-General Survey which is copyrighted/distributed by a commercial publisher (6). Hence CBI is suitable for student's research due to its accessibility. Also, besides assessing the 
personal aspect of exhaustion, CBI also assesses the work and client related aspect of burnout. This serves as an advantage over Maslach Burnout Inventory-General Survey which only emphasised more onto the emotional aspect of exhaustion (6).

The study aimed to determine the prevalence of burnout and its associated factors among medical students in a Malaysian public medical school through the use of CBI.

\section{Methods}

\section{Participants}

A cross-sectional study was conducted on the first to fifth year medical students at the School of Medical Sciences, Universiti Sains Malaysia. Inclusion criteria were Malaysian medical students aged 18 years old and above. They were proficient in English and agreed to participate in the study. Exclusion criteria were non-Malaysian medical students, students who did not give their consents and students who were not proficient in English.

Eligible participants were provided with an information sheet that contained relevant details of the study and informed consent was obtained. Following this, demographic details of participants were recorded.

\section{Ethical Approval}

Ethical approval was obtained from the Human Research Ethics Committee Universiti Sains Malaysia (HREC).

\section{Materials}

Copenhagen Burnout Inventory (CBI) questionnaires were used to carry out the study. A total number of 452 respondents had participated in the study.

For CBI, there are primarily three domains, which include personal burnout, workrelated burnout as well as client-related burnout. Two types of Likerts scale are used. The questions on personal burnout were formulated in a way so that all human beings can answer them (a truly generic scale). The work-related burnout questions assume that the respondent has paid work of some kind. Finally, the client-related burnout questions include the term "client" (or a similar term when appropriate such as patient, students, inmate, etc. (5). There are 12 questions were rated by the Likerts scale ranged from "Always [0]", "Often [1]", "Sometimes [2]", "Seldom [3]", "Never/Almost never [4]"; while there are 7 questions were rated by the Likerts scale ranged from "To a very high degree [0]", "To a high degree [1]", "Somewhat [2]", "To a low degree [3]", "To a very low degree [4]". Reverse scoring was applied in positively worded items. High scores indicated high level of burnout. Mean score was used for interpretation purposes where by a mean score of two or more signified significant burnout.

\section{Study Procedure}

Participants were approached individually via Facebook Messenger through their Facebook account. The data were collected through an online questionnaire developed using Google Forms. The questionnaire was distributed to medical students. They received an informed consent form reassuring them about anonymity, confidentiality, and that published results were solely scientific purpose. Due to the use of online link, all the attempted questionnaires were completed by the participants.

\section{Data and Statistical Analysis}

The statistical analysis was carried out with help of Statistical Package for Social Sciences Software Version 22 (SPSS 22) (IBM Corporation, Armonk, New York, USA). Continuous data were reported as mean and standard deviation. Categorical data were reported as frequency and percentage. Prevalence was calculated using Chi-Square test with the formula $\mathrm{X} / \mathrm{n}$, where " $\mathrm{X}$ " signifies the number of participants who reported significant burnout, and " $n$ " is the total number of participants in this study. 
All descriptive and inferential statistics were generated using SPSS 22. Descriptive statistics were computed to compare the demographical distribution of medical students with regards to the prevalence of significant burnout and its associated factors. Inferential statistics were used to test and estimates relationships between factors and categorical outcome by Chi-Square test. Pearson's Chi-Square to test association between prevalence of burnout and factors (i.e. year of study, gender and ethnic group).

\section{Result}

Out of 810 students, 452 responded the online survey, giving to a $55.8 \%$ response rate (Table 1). The highest response rate was $79.3 \%$ from first year medical students and the lowest response rate was $45.8 \%$ from third year medical students. According to the socio-demographic background of the respondents, $63.1 \%$ were females and $43.1 \%$ were Malays (Table 2).

Out of 452, $307(67.9 \%)$ medical students experienced burnout. Personal burnout was the highest $(81.6 \%)$, followed by work-related burnout $(73.7 \%)$ and client-related burnout (68.6\%) (Figure 1).

Generally, the percentage of burnout across all years of study was between $63.5 \%$ and $73.9 \%$ (Figure 2). Among the three domains of burnout, more than $78.0 \%$ of medical students experienced personal burnout. Analysis showed no significant association between prevalence of burnout and respective year of study $(P=0.573)$.

With regards to gender, a slightly higher number of female medical students reported burnout $(68.10 \%)$ as compared to male medical students $(67.7 \%)$ (Figure 3). The most prevalent domain of burnout in both male and female students was personal burnout, with $81.8 \%$ of female and $81.40 \%$ of male medical students experienced personal burnout. Conversely, male students experienced the least work-related burnout $(70.7 \%)$ and female students experienced
Table 1: Response rate from each year of study

\begin{tabular}{|c|c|c|}
\hline Year of study & Respondents & $\begin{array}{l}\text { Response } \\
\text { rate }\end{array}$ \\
\hline $\begin{array}{l}\text { Year } 1 \\
\text { (Total: } 145 \text { students) }\end{array}$ & 115 & $79.3 \%$ \\
\hline $\begin{array}{l}\text { Year } 2 \\
\text { (Total: } 143 \text { students) }\end{array}$ & 85 & $59.4 \%$ \\
\hline $\begin{array}{l}\text { Year } 3 \\
\text { (Total: } 166 \text { students) }\end{array}$ & 76 & $45.8 \%$ \\
\hline $\begin{array}{l}\text { Year } 4 \\
\text { (Total: } 181 \text { students) }\end{array}$ & 88 & $48.6 \%$ \\
\hline $\begin{array}{l}\text { Year } 5 \\
\text { (Total: } 175 \text { students) }\end{array}$ & 88 & $50.3 \%$ \\
\hline $\begin{array}{l}\text { Year } 1-\text { Year } 5 \\
\text { (Total: } 810 \text { students) }\end{array}$ & 452 & $55.8 \%$ \\
\hline
\end{tabular}

Table 2: Socio-demographic background of the participants across all years of study

\begin{tabular}{lcl}
\multicolumn{1}{c}{ Variable } & $\mathbf{n}$ & $\%$ \\
\hline $\begin{array}{l}\text { Total participants } \\
\text { Gender }\end{array}$ & 452 & 100 \\
$\quad$ Male & 167 & 36.9 \\
$\quad$ Female & 285 & 63.1 \\
Ethnicity & & \\
Malay & 195 & 43.1 \\
Chinese & 174 & 38.5 \\
Indian & 66 & 14.6 \\
Others & 17 & 3.8 \\
Year of study & & \\
$1^{\text {st }}$ Year MD & 115 & 25.4 \\
$2^{\text {nd }}$ Year MD & 85 & 18.8 \\
$3^{\text {rd }}$ Year MD & 76 & 16.8 \\
$4^{\text {th }}$ Year MD & 88 & 19.5 \\
$5^{\text {th }}$ Year MD & 88 & 19.5 \\
\hline
\end{tabular}

the least client-related burnout $(67.0 \%)$. Analysis showed no significant association between prevalence of burnout and gender $(P=0.930)$.

With regard to ethnic group, overall burnout was higher among the Malays (68.7\%) as compared to the non-Malay $(67.3 \%)$ students (Figure 4). Among the three 


\section{Prevalence of Significant Burnout and Its Domain among USM Medical Students}

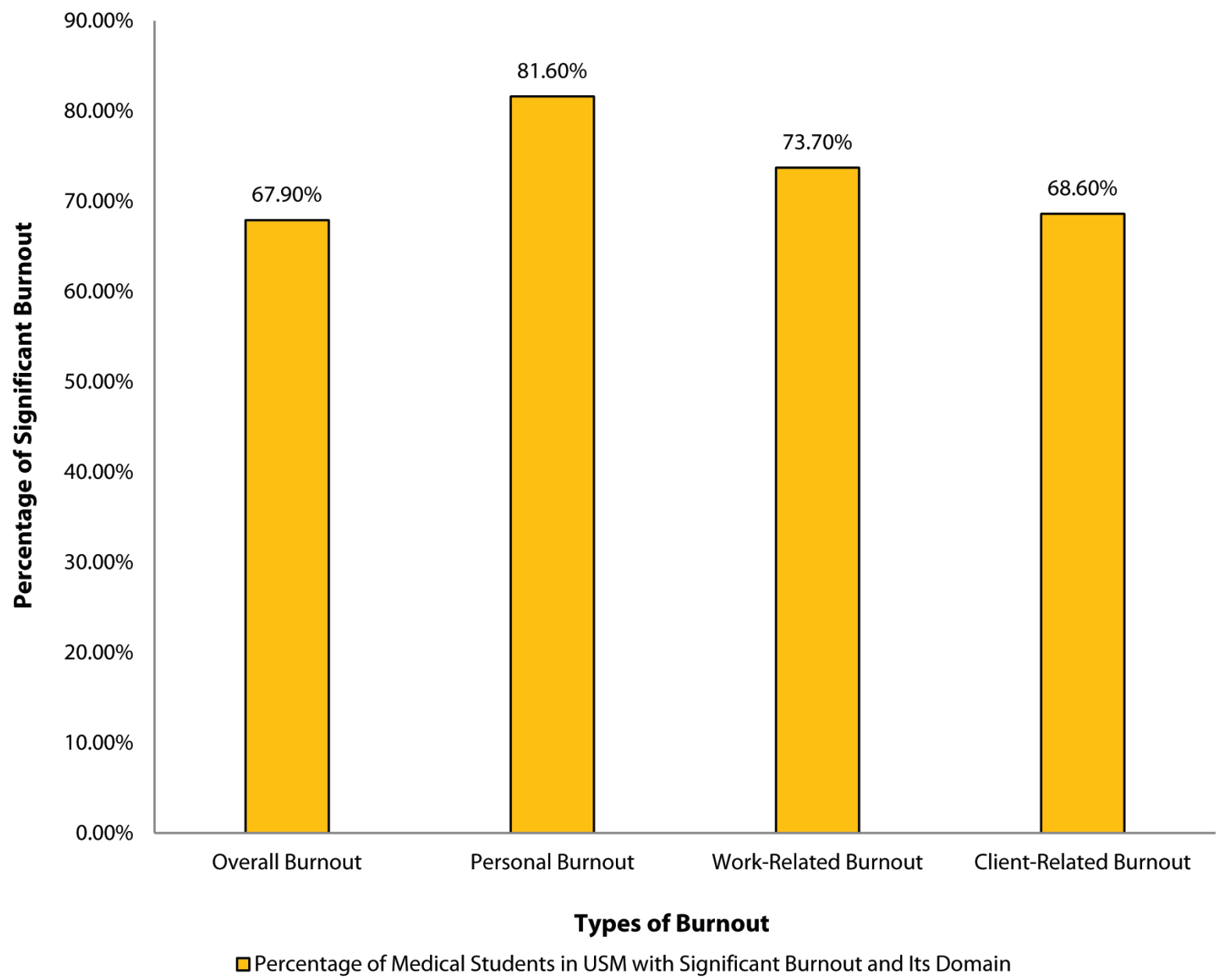

Figure 1: Prevalence of significant burnout and its domain among USM medical students based on CBI.

domains of burnout, personal burnout was the most prevalent for Malays ( $81 \%$ ) and also the non-Malay $(82.1 \%)$ medical students. Whereas, client related burnout was the least experienced burnout i.e. $65.6 \%$ of Malays and $70.8 \%$ non-Malay medical students. Analysis showed no significant association between ethnic group and prevalence of burnout $(P=0.752)$.

\section{Discussion}

This study revealed that the prevalence of burnout among USM medical students was high i.e. more than $50 \%$. This result is consistent with the previous finding that reported more than half of the medical students experienced burnout (10,14-16). Interestingly, regardless of gender, ethnic group, and year of study, medical students were equally vulnerable to experience burnout, indicating that medical schools' administrator should start looking at this as an area of concern which likely need immediate intervention.

About $67.9 \%$ of USM medical students experienced burnout and the figure is higher than Pakistani medical students (i.e. $35.9 \%$ ) as measured by the same burnout inventory (17). In addition, this study found that personal burnout was the most prevalent (i.e. more than $80 \%$ ), indicating 


\section{Prevalence of Significant Burnout among USM Medical Students in Each} Year of Study

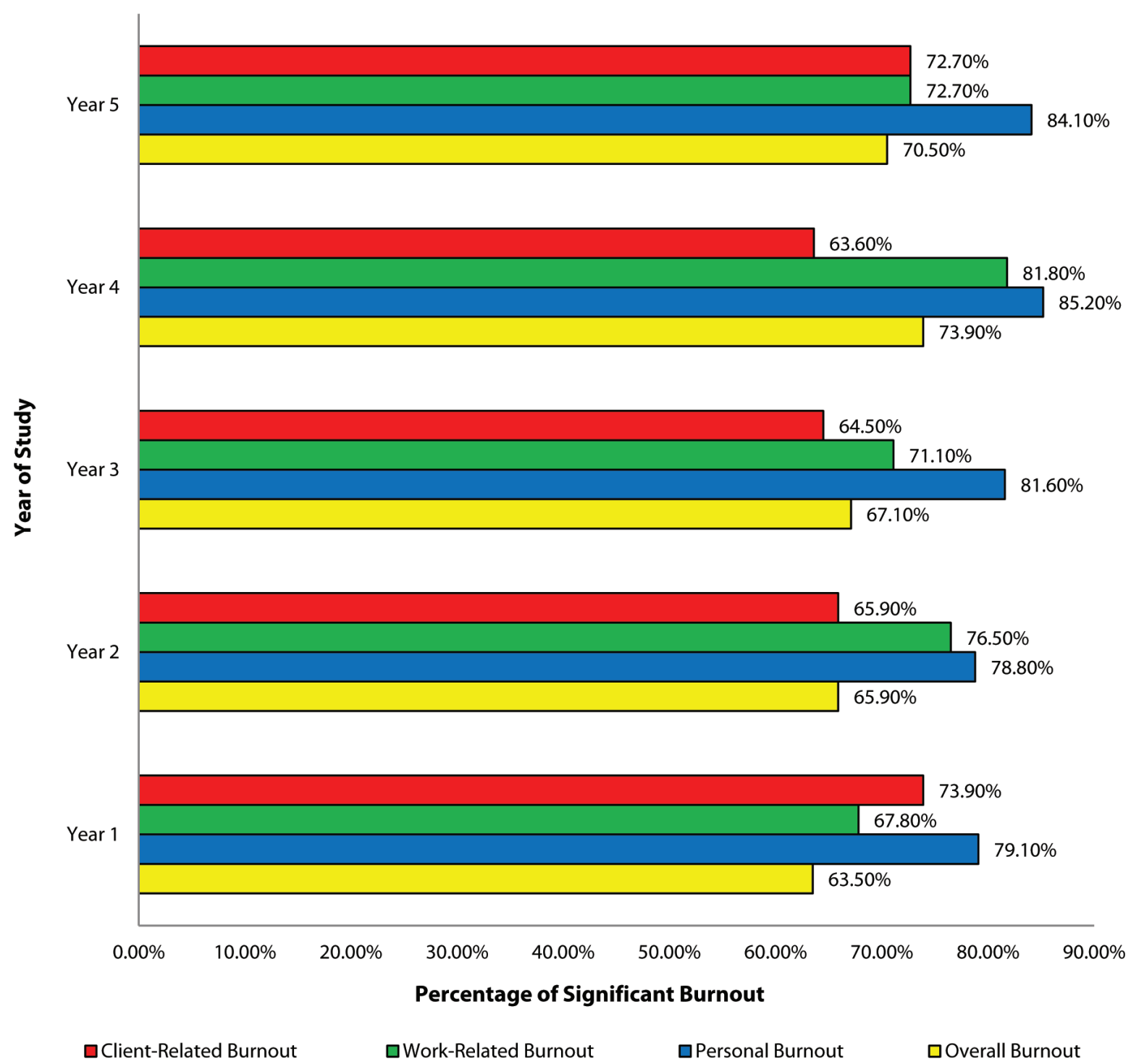

Figure 2: Prevalence of significant burnout among USM medical students in each year of study based on CBI (Client-Related: $X^{2}=4.101, p$-value $=0.393$; Work-Related: $X^{2}=5.690, p$-value $=0.224$; Personal: $X^{2}=2.041$, $p$-value $=0.728 ;$ Overall: $\mathrm{X}^{2}=2.913, p$-value $=0.573$ ).

students experienced high depersonalisation symptoms. A recent review on burnout among US medical students reported a lower level of depersonalisation ranged from $26 \%$ to $38 \%$ (10), however, the burnout was measured by Maslach Burnout Inventory. These facts suggest that the burnout experienced by USM medical students is alarmingly higher than other medical students, and therefore immediate measures should be introduced because a special intervention program was shown to have beneficial effect on the medical students' psychological health (18).

The prevalence of burnout was highest in Year 4 medical students, especially personal and work-related burnout. In USM medical school setting, Year 4 is the transition period from pre-clinical years to clinical years and therefore it requires them to adapt 


\section{Prevalence of Significant Burnout among Different Gender of USM Medical Students}

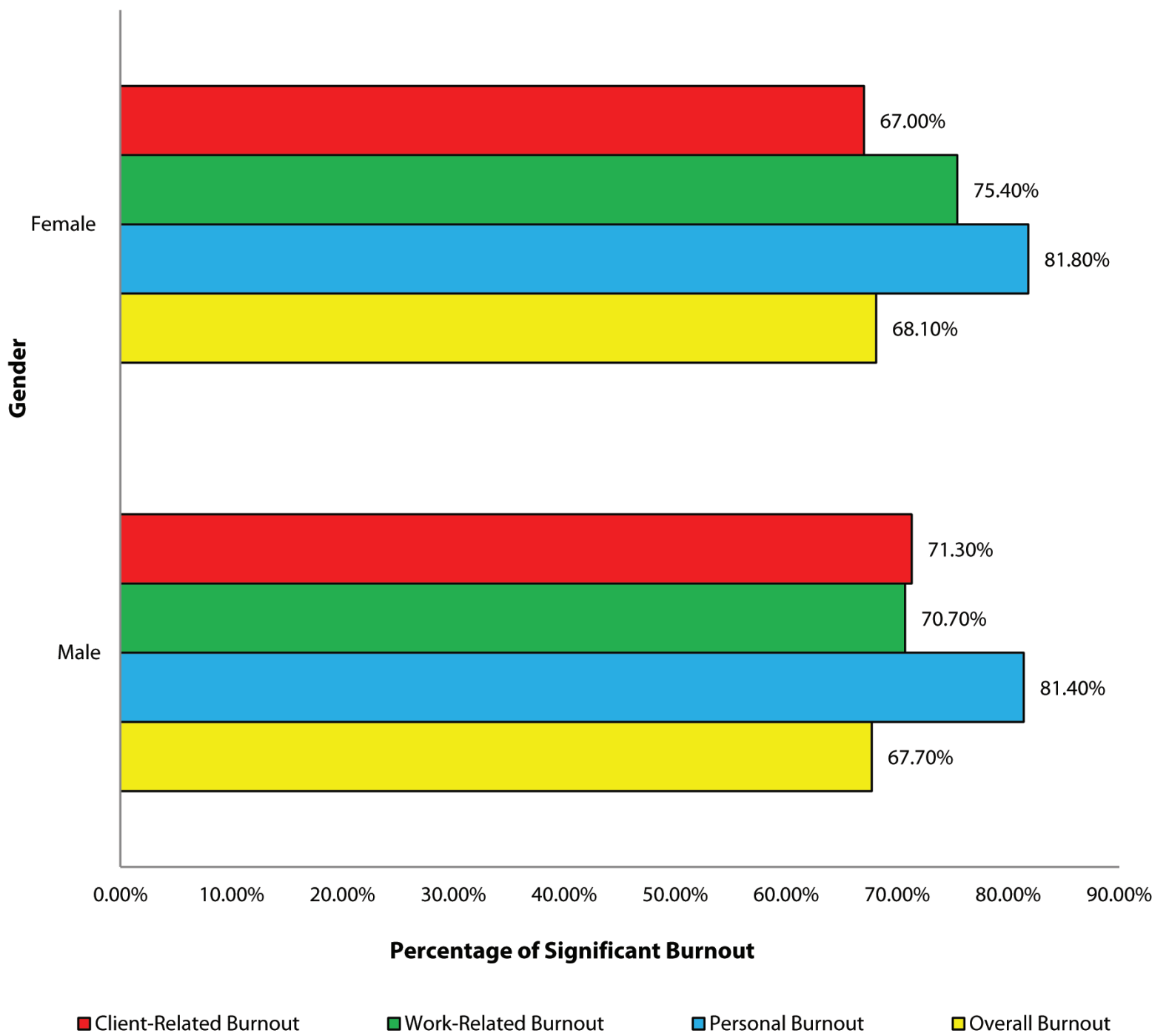

Figure 3: Prevalence of significant burnout among different gender of USM medical students based on CBI (Client-Related: $\mathrm{X}^{2}=0.879, p$-value $=0.349$; Work-Related: $\mathrm{X}^{2}=1.240, p$-value $=0.265$; Personal: $\mathrm{X}^{2}=0.007$, $p$-value $=0.933$; Overall: $\mathrm{X}^{2}=0.008, p$-value $\left.=0.930\right)$.

quickly in a new learning environment but this can cause unwanted stress (7). In addition, the patient-centered approach of learning (i.e. ward works and on-calls) will add more stress on them that lead to personal burnout and work-related burnout. This finding is similar to a previous study that reported senior medical students at Year 4 and Year 5 experienced more stresses than other years (19).
Apart of that, the prevalence of clientrelated burnout was highest in Year 1 medical students followed closely by Year 5 students. In this context, clients were referred to the person to whom the respondents spent most of their time with during the academic session, for example lecturers, patients and friends. The client-related burnout among Year 1 medical students could be a result of having difficulties in adapting to 


\section{Prevalence of Significant Burnout among Different Ethnicity of USM Medical Students}

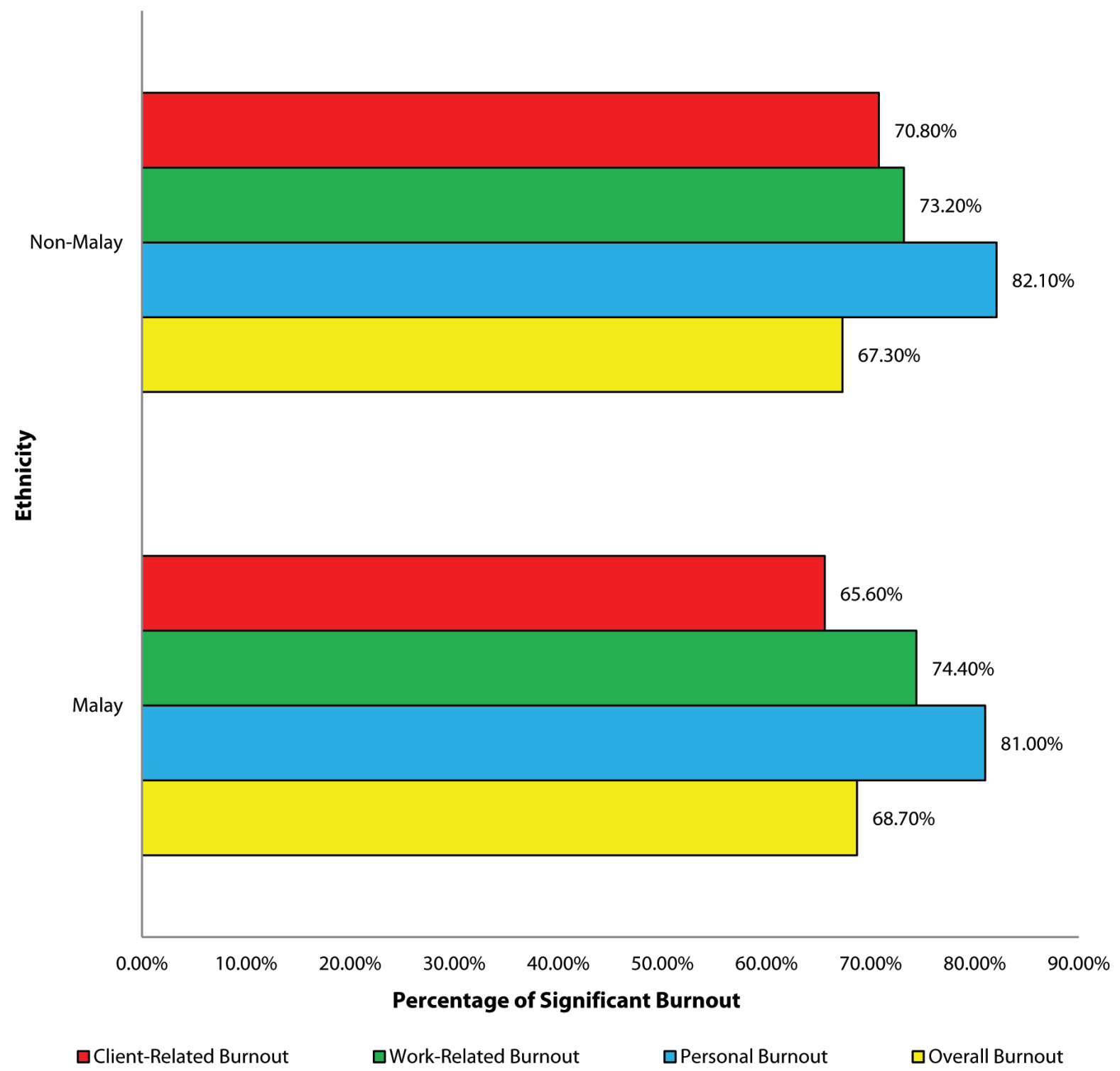

Figure 4: Prevalence of significant burnout among different ethnicity of USM medical students based on CBI (Client-related: $\mathrm{X}^{2}=1.379, p$-value $=0.240 ;$ Work-Related: $\mathrm{X}^{2}=0.083, p$-value $=0.773 ;$ Personal: $\mathrm{X}^{2}=0.086$, $p$-value $=0.770 ;$ Overall: $X^{2}=0.100, p$-value $\left.=0.752\right)$.

lecturers' teaching style which was different from that of their pre-university institution. In addition, there was likely inadequate academic assistance from their seniors in view of the newly-implemented curriculum. Perhaps, special intervention programs could be arranged to address the client-related burnout through educational strategies (10) such as the DEAL-based program that was reported to improve psychological health of medical students $(18,20,21)$. Besides, it is worth noting that, although not statistically significant, a higher number of female medical students reported burnout $(68.10 \%)$ than male medical students (67.7\%). This finding is comparable with a study that found approximately $50 \%$ of female and $33 \%$ of male medical students experienced 
psychological stress (22). This finding indicates that the educational strategies should be designed to address different gender needs.

To shed some light on burnout among medical students, several explanations might be offered based on the coping reservoir model that is useful to describe coping capabilities and subsequent well-being of medical student (23). The model describes two main factors that contribute to wellbeing or burnout that include depleting factors (i.e. negative input such as stress, internal conflicts, and time and energy demands) and replenishing factors (i.e. positive factors such as psychosocial support, healthy activities, intellectual stimulation and mentorship) (23). According to this model, burnout occurs when the depleting factors are more than the replenishing factors. Therefore, based on this model, the best way to address burnout is to design an educational program that is able to increase replenishing factors and to reduce depleting factors.

According to a multi-institutional study done in the United States on burnout and suicidal ideation among medical students (15), burnout demonstrated a strong dose-response relationship with suicidal ideation. This association also satisfied both the temporality requirement (burnout preceded suicidal ideation) and the criteria for reversibility (risk for suicidal ideation returned to baseline with recovery from burnout). Hence establishes an association between burnout and suicidal ideation among medical students. Suicide is at the extreme end of the personal distress continuum, and it is critical for medical schools to identify students at greatest risk for suicide in the hope of intervening before a tragic outcome.

The study had a few limitations, which should be considered in future research. Firstly, our response rate was only $55.80 \%$, one would hypothesise that distressed students may be less motivated to fill out a survey or that they would be more likely to participate because the topic is relevant to them. Hence, selection bias is a possibility. Furthermore, this study was conducted in only one medical school, thus further researches should use a multi-centric approach to study burnout phenomenon among medical students in Malaysia. Also, the cross-sectional design of this study limits deduction about causality and temporality.

Due to limited amount of prevalence studies of burnout among medical students; it is highly recommended that it should be conducted to assess burnout level of medical students since medicine is often considered as the toughest undergraduate course to pursue. Should the prevalence of burnout turn out high, then further investigations can be undertaken to determine the causative factors for the high burnout rate among medical students, hence early intervention can be introduced to prevent consequences of burnout.

\section{Conclusion}

The prevalence of burnout among USM medical students is high and the most prevalent type of burnout across all years of study is personal burnout. Regardless of gender, ethnicity and year of study, medical students are similarly vulnerable to experience burnout.

We believed that a significant proportion of these burnout students may be at risk of getting depression or even suicidal ideation later on but this needs further studies. For both mental and social well-being of future doctors, the problem of burnout should be a concern for the school administration.

Further studies are encouraged to venture into the causative factors that leads to the high prevalence of burnout among medical students. 


\section{Appendix A}

\section{Copenhagen Burnout Inventory (CBI)}

1(a) How often do you feel tired?
(0) Always
(1) Often
(2) Sometimes
(3) Seldom
(4) Never/Almost never

1(b) How often are you physically exhausted?
(0) Always
(1) Often
(2) Sometimes
(3) Seldom
(4) Never/Almost never

1(c) How often are you emotionally exhausted?
(0) Always
(1) Often
(2) Sometimes
(3) Seldom
(4) Never/Almost never

1(d) How often do you think: "I can't take it anymore"?
(0) Always
(1) Often
(2) Sometimes
(3) Seldom
(4) Never/Almost never

1(e) How often do you feel worn out?

(0) Always

(1) Often

(2) Sometimes

(3) Seldom

(4) Never/Almost never

1(f) How often do you feel weak and susceptible to illness?

(0) Always

(1) Often

(2) Sometimes

(3) Seldom

(4) Never/Almost never

2(a) Is your work emotionally exhausting?

(0) To a very high degree

(1) To a high degree

(2) Somewhat

(3) To a low degree

(4) To a very low degree

2(b) Do you feel burnt out because of your work?

(0) To a very high degree

(1) To a high degree

(2) Somewhat

(3) To a low degree

(4) To a very low degree 
2(c) Does your work frustrate you?

(0) To a very high degree

(1) To a high degree

(2) Somewhat

(3) To a low degree

(4) To a very low degree

2(d) Do you feel worn out at the end of the working day?

(0) Always

(1) Often

(2) Sometimes

(3) Seldom

(4) Never/Almost never

2(e) Are you exhausted in the morning at the thought of another day at work?

(0) Always

(1) Often

(2) Sometimes

(3) Seldom

(4) Never/Almost never

2(f) Do you feel that every working hour is tiring for you?

(0) Always

(1) Often

(2) Sometimes

(3) Seldom

(4) Never/Almost never 2(g) Do you have enough energy for family and friends during leisure time?

(0) Always

(1) Often

(2) Sometimes

(3) Seldom

(4) Never/Almost never

3(a) Do you find it hard to work with clients?

(0) To a very high degree

(1) To a high degree

(2) Somewhat

(3) To a low degree

(4) To a very low degree

3(b) Do you find it frustrating to work with clients?

(0) To a very high degree

(1) To a high degree

(2) Somewhat

(3) To a low degree

(4) To a very low degree

3(c) Does it drain your energy to work with clients?

(0) To a very high degree

(1) To a high degree

(2) Somewhat

(3) To a low degree

(4) To a very low degree 
3(d) Do you feel that you give more than you get back when you work with clients?

(0) To a very high degree
(1) To a high degree
(2) Somewhat
(3) To a low degree
(4) To a very low degree

3(e) Are you tired of working with clients?

(0) Always

(1) Often

(2) Sometimes

(3) Seldom

(4) Never/Almost never 3(f) Do you sometimes wonder how long you will be able to continue working with clients?
(0) Always
(1) Often
(2) Sometimes
(3) Seldom
(4) Never/Almost never 


\section{References}

1. Schaufeli WB, Greenglass ER. Introduction to special issue on burnout and health. Psychology \& health. 2001;16(5):501-10. http://dx.doi.org/10.1080/0887044010840 5523.

2. Malakh-Pines A, Aronson E. Career burnout: causes and cures: Free Press; 1988.

3. Shirom A. Burnout in work organizations. In: Cary L. Cooper ITR, editor. International review of industrial and organizational psychology 4. New York: John Wiley and Sons; 1989. p. 26-48.

4. Lundgren-Nilsson A, Jonsdottir IH, Pallant J, Ahlborg G, Jr. Internal construct validity of the Shirom-Melamed Burnout Questionnaire (SMBQ). BMC Public Health. 2012;12:1. http://dx.doi.org/10.1186/1471-2458-12-1.

5. Kristensen TS, Borritz M, Villadsen E, Christensen KB. The Copenhagen burnout inventory: a new tool for the assessment of burnout. Work \& Stress. 2005;19(3):192-207. http://dx.doi.org/10. 1080/02678370500297720.

6. Lee YY, Medford AR, Halim AS. Burnout in physicians. The Journal of the Royal College of Physicians of Edinburgh. 2015;45(2):104-7. http://dx.doi.org/10.4997/JRCPE.2015.203.

7. Yusoff MSB, Abdul Rahim AF, Yaacob MJ. Prevalence and sources of stress among Universiti Sains Malaysia medical students. The Malaysian Journal of Medical Sciences. 2010;17(1):30-7.

8. Yusoff MSB, Abdul Rahim AF, Baba $\mathrm{AA}$, Ismail SB, Mat $\mathrm{Pa} \mathrm{MN}$, Esa AR. Prevalence and associated factors of stress, anxiety and depression among prospective medical students. Asian Journal of Psychiatry. 2013;6(2):128-33. http://dx.doi. org/10.1016/j.ajp.2012.09.012.
9. Yen Yee L, Yusoff MSB. Prevalence and sources of stress among medical students in Universiti Sains Malaysia and Universiteit Maastricht. Education in Medicine Journal. 2013;5(4):34-41. http://dx.doi.org/10.5959/ eimj.v5i4.190.

10. Dyrbye L, Shanafelt T. A narrative review on burnout experienced by medical students and residents. Med Educ. 2016;50(1):132-49. http://dx.doi.org/10.1111/medu.12927.

11. Puthran R, Zhang MWB, Tam WW, Ho RC. Prevalence of depression amongst medical students: a meta-analysis. Medical Education. 2016;50(4):456-68. http://dx.doi. org/10.1111/medu.12962.

12. Smith CK, Peterson DF, Degenhardt BF, Johnson JC. Depression, anxiety, and perceived hassles among entering medical students. Psychology, Health \& Medicine. 2007;12(1):31-9. http://dx.doi. org/10.1080/13548500500429387.

13. Dyrbye LN, Thomas MR, Massie FS, Power DV, Eacker A, Harper W, et al. Burnout and suicidal ideation among U.S. medical students. Annals of Internal Medicine. 2008;149(5):334-41. http://dx.doi.org/10. 7326/0003-4819-149-5-200809020-00008.

14. Santen SA, Holt DB, Kemp JD, Hemphill RR. Burnout in medical students: examining the prevalence and associated factors. Southern Medical Journal. 2010;103(8):758-63. http://dx.doi.org/10.1097/SMJ.0b013e3181 e6d6d4.

15. Dyrbye LN, Thomas MR, Massie FS, Power DV, Eacker A, Harper W, et al. Burnout and suicidal ideation among U.S. medical students. Ann Intern Med. 2008;149(5):334-41. http://dx.doi.org/10. 7326/0003-4819-149-5-200809020-00008.

16. Cecil J, McHale C, Hart J, Laidlaw A. Behaviour and burnout in medical students. Medical Education Online. 2014;19:25209. http://dx.doi.org/10.3402/meo.v19.25209. 
17. Muzafar $\mathrm{Y}$, Khan $\mathrm{HH}$, Ashraf $\mathrm{H}$, Hussain W, Sajid H, Tahir M, et al. Burnout and its associated factors in medical students of Lahore, Pakistan. Cureus. 2015;7(11):e390. http://dx.doi.org/10.7759/cureus.390.

18. Yusoff MSB. Interventions on medical students' psychological health: a metaanalysis. Journal of Taibah University Medical Sciences. 2014;9(1):1-13. http://dx.doi.org/ 10.1016/j.jtumed.2013.09.010.

19. Shaikh BT, Kahloon A, Kazmi M, Khalid H, Nawaz K, Khan N, et al. Students, stress and coping strategies: a case of Pakistani medical school. Education for Health (Abingdon, England). 2004;17(3):346-53. http://dx.doi. org/10.1080/13576280400002585.

20. Yusoff MSB, Yaacob MJ, Naing NN, Esa AR. The effectiveness of a DEAL-based intervention to reduce stress and depression symptoms. Education in Medicine Journal. 2015;7(1):1-15. http://dx.doi.org/10.5959/ eimj.v6i4.282.
21. Yusoff MSB, Esa AR. A DEAL-based intervention for the reduction of depression, denial, self-blame and academic stress: a randomized controlled trial. Journal of Taibah University Medical Sciences. 2015; 10(1):82-92. http://dx.doi.org/10.1016/j. jtumed.2014.08.003.

22. Backovic DV, Zivojinovic JI, Maksimovic J, Maksimovic M. Gender differences in academic stress and burnout among medical students in final years of education. Psychiatria Danubina. 2012;24(2):175-81.

23. Dunn LB, Iglewicz A, Moutier C. A conceptual model of medical student wellbeing: promoting resilience and preventing burnout. Academic Psychiatry: The Journal of The American Association of Directors of Psychiatric Residency Training and The Association for Academic Psychiatry. 2008;32(1):44-53. http://dx.doi.org/10.1176/ appi.ap.32.1.44. 